\title{
NEW FLUORINATED ERYTHROMYCINS OBTAINED BY MUTASYNTHESIS
}

\author{
Luciano Toscano*, Giuseppe Fioriello \\ Department of Chemistry \\ Roberto Spagnoli ${ }^{\dagger}$, Leonardo Cappelletti ${ }^{\dagger \dagger}$ \\ Department of Microbiology \\ Giovanna Zanuso \\ Department of Biology \\ Pierrel S.p.A., Research Laboratories \\ Via Degli Artigianelli, 10, 20159 Milan, Italy \\ (Received for publication April 27, 1983)
}

\begin{abstract}
Following the previously described semisynthetic preparation of new aglycones (8S)-8fluoroerythronolide A (I), (8S)-8-fluoroerythronolide B (II) and the monoglycoside 3-Omycarosyl-(8S)-8-fluoroerythronolide B (III), their conversion into new fluoroerythromycins was attempted by mutational biosynthesis. The strain Streptomyces erythraeus ATCC 31772, a mutant blocked in the biosynthesis of erythromycin, was employed in the present investigation. Four new antibiotics, (8S)-8-fluoroerythromycin A (IV), (8S)-8-fluoroerythromycin $\mathrm{B}$ (V), (8S)-8-fluoroerythromycin C (VI) and (8S)-8-fluoroerythromycin D (VII) were successfully derived by such an approach. The result is also discussed in terms of the substrate specificity of the enzymes involved in the biosynthesis of erythromycins. The new antibiotics exhibited promising biological properties.
\end{abstract}

During the last twenty years advances in organic fluorine chemistry have been responsible for the development of a large number of new compounds of importance in biology and medicine. Replacement of an atom of hydrogen by one of fluorine in organic molecules may profoundly change their biological properties ${ }^{1,2)}$. The rationale employed is that, since hydrogen and fluorine are nearly isosteric, the fluoro analog would be expected to have little difficulty in fitting onto active sites of receptors. At the same time, the strong electronegativity of the fluorine atom, when strategically placed, could be used to make defined alterations in the biological activity.

As part of a general strategy of our laboratories aimed at the synthesis of fluorinated organic derivatives designed as potential drugs, we have undertaken a program involving the synthesis and the biological evaluation of new fluoroerythromycins.

In previous papers ${ }^{3,4)}$ we have reported the fluorination of enol ether groups in 8,9-anhydroerythronolide A and B 6,9-hemiketals and 3-O-mycarosyl-8,9-anhydroerythronolide B 6,9-hemiketal with trifluoromethyl hypofluorite. This reaction, already employed for the introduction of fluorine into naturally occurring products ${ }^{5 \sim 10}$, was of interest per se and also as model to be used in the erythromycin series. These fluorinations were achieved under mild conditions to give (8S)-8-fluoroerythronolides A (I) and B (II) and 3-O-mycarosyl-(8S)-8-fluoroerythronolide B (III). Moreover, in contrast to ery-

\footnotetext{
Present addresses:

† Roussel Uclaf, Biotechnology Department, 93230 Romainville, France.

t† Bristol-Myers Industrial Division, Syracuse, NY13201, USA.
} 
Scheme 1.
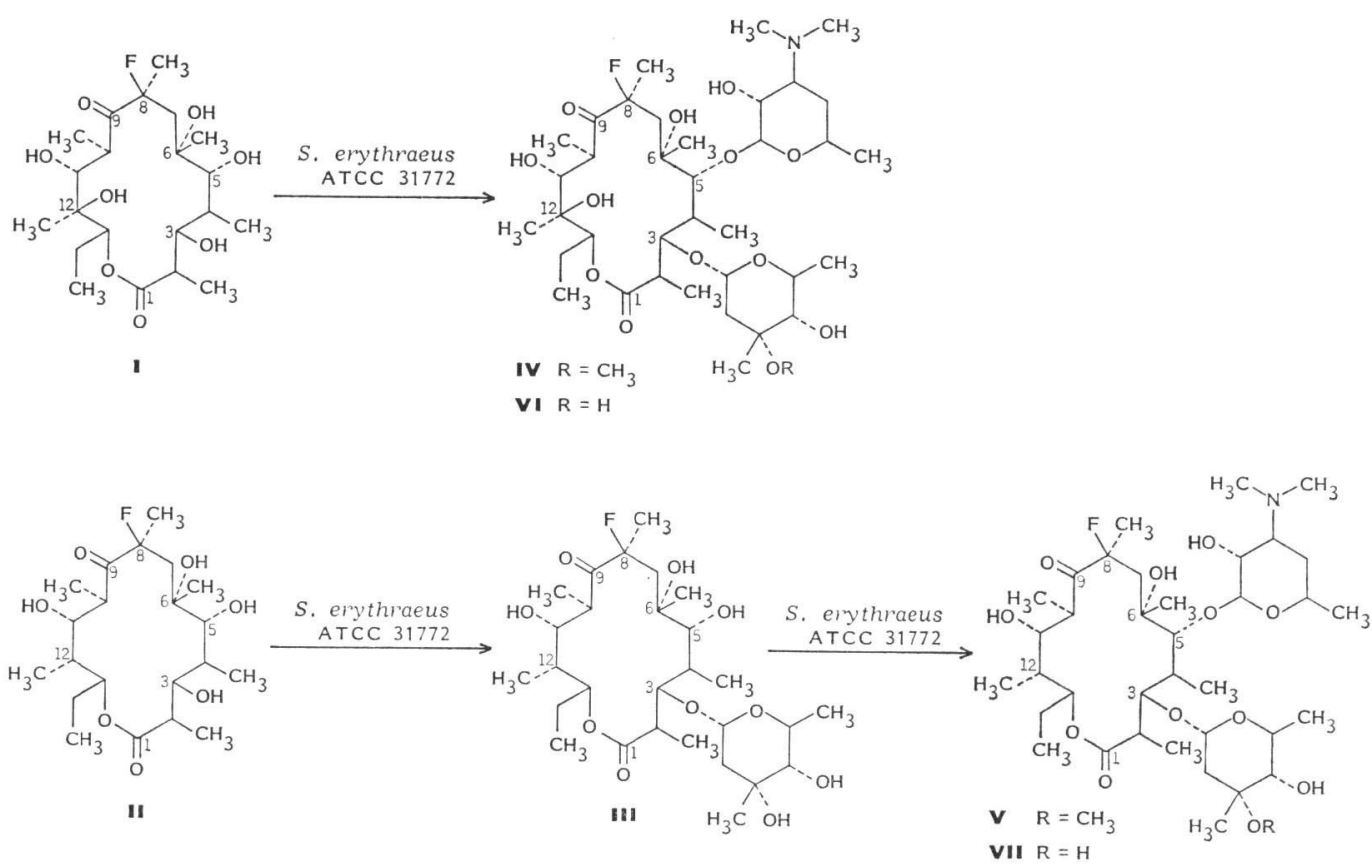

thronolide A, (8S)-8-fluoroerythronolide A (I) was shown to be stable in mineral acid solution ${ }^{32}$. Since the acid degradation pattern of erythromycin $\mathrm{A}^{11)}$ closely resembles that of erythronolide $\mathrm{A}^{12)}$, we thought to synthesize the (8S)-8-fluoroerythromycin A (IV) with the aim of obtaining a compound with same antibacterial activity as erythromycin $\mathrm{A}$ but with an enhanced stability to acids ${ }^{13}$. However, when we carried out an analogous fluorination ${ }^{4}$ on the enol ether group of 8,9-anhydroerythromycin A and $\mathrm{B}$ 6,9-hemiketals ${ }^{11}$, the complete range of the reaction products could not be characterized because of difficulties encountered in the attempted isolation.

Instead, the new (8S)-8-fluoroerythromycins IV, V, VI and VII (Scheme 1) could be obtained by a mutasynthetic approach ${ }^{14}$, individually adding the fluoro-compounds I, II, III, in the fermentation medium of Streptomyces erythraeus ATCC 31772, a mutant blocked in erythromycin biosynthesis. This strain was previously ${ }^{15)}$ shown to produce erythromycins A and B when fed erythronolides A and B.

In this paper the fermentative production, isolation, physico-chemical properties, antibacterial activity and some preliminary absorption studies in rats of these antibiotics are presented.

\section{Results and Discussion}

Bioconversion of (8S)-8-Fluoroerythronolide A (I)

Two active compounds IV and VI (Scheme 1) were obtained when (8S)-8-fluoroerythronolide A (I) was added to the fermentation broth of S. erythraeus ATCC 31772, a blocked mutant of an erythromycinproducing strain. The structures of IV and VI were determined to be (8S)-8-fluoroerythromycin A and (8S)-8-fluoroerythromycin C, respectively, on the basis of elemental analyses, fast atom bombardment (FAB) mass spectral data and behavior to the acids. FAB-mass spectrometry (MS) has been shown ${ }^{16 \sim 18)}$ to be the method of choice in determining molecular weights of a number of non-volatile or 
Scheme 2.

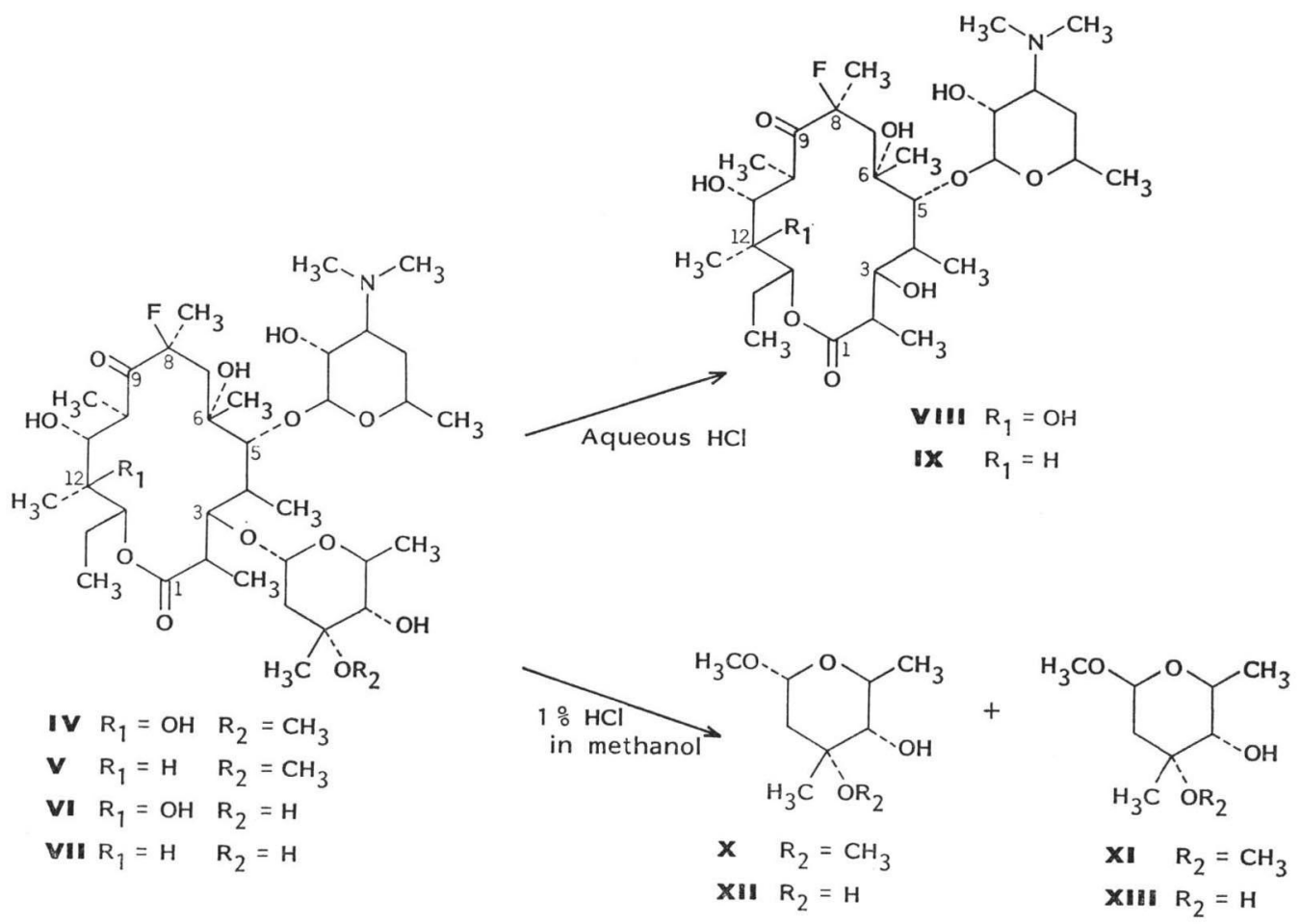

thermally unstable antibiotics.

The microanalyses (C, H, F and N) of IV and VI were in agreement with the molecular formulas $\mathrm{C}_{37} \mathrm{H}_{66} \mathrm{FNO}_{13}$ and $\mathrm{C}_{38} \mathrm{H}_{64} \mathrm{FNO}_{13}$, respectively. FAB-MS of IV and VI showed good pseudomolecular ion sensitivity and fragmentations that could be interpreted on the basis of chemical ionization or electronic impact mass spectral data reported ${ }^{19 \sim 21)}$ before for natural erythromycins. FAB-MS of IV gave the protonated molecular ion at $m / z 752$ that was also the base peak. The fragmentation pattern showed the presence of peaks at $m / z 734\left(\mathrm{MH}^{+}-\mathrm{H}_{2} \mathrm{O}\right)$, and $m / z 594$ and 576 accounting for the removal of cladinose from the protonated molecular ion, with or without the glycosidic oxygen atom, respectively. The glycosidic fragmentations were substantiated by metastable ion peaks at the appropriate mass values (469.2 and 441.2). The fragments at $m / z 174$ and 158 indicated the presence of desosamine, while those at $m / z 159,127$ and 109 were characteristic of cladinose. FAB-MS of VI gave the protonated molecular ion at $m / z 738$, while the peak at $m / z 720$ was due to ion $\mathrm{MH}^{+}-\mathrm{H}_{2} \mathrm{O}$. The fragmentation pattern was analogous to that showed by (8S)-8-fluoroerythromycin A. Peaks at $m / z 145,127$ and 109 showed that the sugar at C-3 was mycarose. When IV and VI were treated with dilute hydrochloric acid (Scheme 2), according to the method described in previous papers ${ }^{22,23)}$, they afforded a common monoglycoside, whose elemental analysis, FAB-mass and ${ }^{1} \mathrm{H}$ NMR spectral data were consistent with structure VIII of 5-O-desosaminyl-(8S)-8-fluoroerythronolide A. Acid-catalyzed methanolysis of IV led to the mixture of the $\alpha$ - and $\beta$-anomers ( $\mathbf{X}$ and XI) of methyl cladinoside ${ }^{24)}$ as with erythromycin A. In an analogous way, both VI and 3-O-mycarosylerythronolide B afforded the $\alpha$ - and $\beta$-anomers (XII and XIII) of methyl mycaroside ${ }^{25)}$. 
Scheme 3.
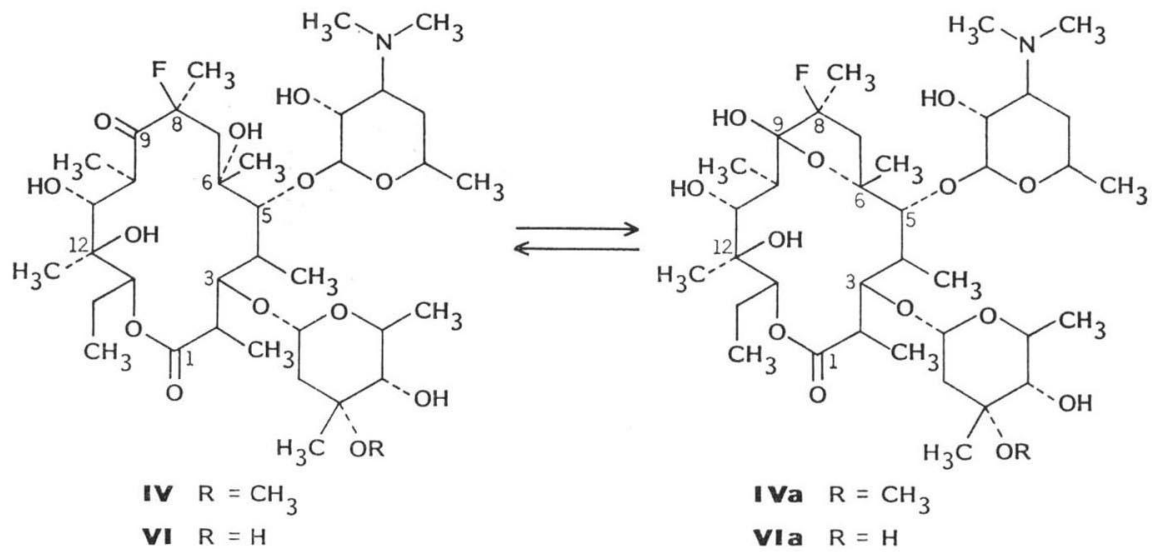

Although (8S)-8-fluoroerythromycin A (IV) showed a single spot in several TLC systems, its ${ }^{1} \mathrm{H}$ NMR and ${ }^{13} \mathrm{C}$ NMR spectra in pyridine- $d_{5}$ and deuteriochloroform, respectively, revealed a duality of resonances indicative of a mixture of two components. In both solvents, and particularly in pyridine$d_{5}$ where the effect was most pronounced, a temperature dependent reversible change in the proportions of the two components was observed. In aqueous acid solution, HPLC analysis (mobile phase 2) evidenced an analogous phenomenon with formation of two peaks at 4.01 (UV maximum at $288 \mathrm{~nm}$ ) and 3.44 minutes (no UV maximum). These and previously reported results ${ }^{28}{ }^{2 \theta}$ ) suggested that the two components of (8S)-8-fluoroerythromycin A were the fluoroketone IV and the hemiketal IVa (Scheme 3). The structure of the hemiketal IVa was determined by ${ }^{18} \mathrm{C}$ NMR analysis. In deuteriochloroform solution, where the hemiketal form was predominant, the formation of a 6,9-oxygen bridge resulted in C-6 and C-9 chemical shifts at 83.0 and $106.3 \mathrm{ppm}\left(J_{\mathrm{FC}-9}=20.6 \mathrm{~Hz}\right.$, characteristic $\left.{ }^{80}\right)$ carbon-fluorine coupling constant for the $\beta$-carbons), reminiscent of the corresponding chemical shifts observed for the 6,9methylketal of (8S)-8-hydroxyerythromycin $\mathrm{A}^{31)}$ and the 6,9-hemiketal of 5-deoxy-5-oxoerythronolide $\mathrm{B}^{32)}$. Analogous fluoroketone (VI) - hemiketal (VIa) tautomerism was exhibited by (8S)-8-fluoroerythromycin C (Scheme 3).

The mutasynthetic approach using modified lactones derived from the aglycone of erythromycin was rarely successful, mainly because of the specificity of the desosamine-binding enzyme ${ }^{33 \sim 35)}$. To our knowledge, only the 11-O-methyl ether of erythronolide B was previously reported ${ }^{38)}$ to yield a bisglycoside, the 11-O-methylerythromycin B. The successful conversion of (8S)-8-fluoroerythronolide A (I) indicates that the fluorine atom at $\mathrm{C}-8$ does not introduce significant steric and conformational changes in the structure of the aglycone, which still has a facile permeation through the cell membrane and is recognized by the glycosidating enzymes. Before this experiment, we already described ${ }^{15}$ ) the obtainment of a bisglycoside by feeding erythronolide A to S. erythraeus ATCC 31772. The latter substrate was quantitatively converted to erythromycin A. In the present experiment, a mixture of (8S)-8fluoroerythromycins $\mathrm{A}(\mathbf{I V})$ and $\mathrm{C}(\mathbf{V I})$ in approximatively equimolar amounts was produced when $(8 S)$ 8-fluoroerythronolide A (I) was added to a culture of that same strain. This suggests that $O$-methylation is a rate-limiting step due to the high substrate specificity of the $S$-adenosyl-L-methionine transmethylase and this activity is negatively affected by the fluorine atom in the substrate. 
Bioconversion of (8S)-8-Fluoroerythronolide B (II) and 3-O-Mycarosyl-( $8 S$ )-

\section{8-fluoroerythronolide B (III)}

Two active bioconvertants V and VII (Scheme 1) were produced when either (8S)-8-fluoroerythronolide B (II) or 3-O-mycarosyl-(8S)-8-fluoroerythronolide B (III) was added to the culture of S. erythraeus ATCC 31772. On TLC and HPLC analysis of the broth culture fed II, it was possible to detect a compound with same chromatographic behavior as III, which disappeared with increasing time of incubation. In analogy to the corresponding biosynthesis of erythromycin ${ }^{37)}$, it is reasonable to assume that III is a biosynthetic intermediate in the transformation of II to $\mathbf{V}$ (Scheme 1). The structures of $\mathbf{V}$ and VII were deduced from their elemental analyses, FAB-mass spectral data and behavior to the acids.

The elemental analysis $\left(\mathrm{C}, \mathrm{H}, \mathrm{F}\right.$ and $\mathrm{N}$ ) of $\mathbf{V}$ accorded with the formula $\mathrm{C}_{37} \mathrm{H}_{66} \mathrm{FNO}_{12}$.

Its FAB-MS gave the protonated molecular ion at $m / z$ 736. A prominent ion at $m / z 718$ attributed to $\mathrm{MH}^{+}-\mathrm{H}_{2} \mathrm{O}$ was present. Metastable ion peaks at the appropriate mass values (453.9 and 426.0) were also present, indicating the direct loss of cladinose from the protonated molecular ion, either with ( $m / z 578)$ or without $(m / z 560$, base peak) its glycosidic oxygen atom. The occurrence of peaks corresponding to those observed for ( $8 S$ )-8-fluoroerythromycin $\mathrm{A}$, proved that the sugars at $\mathrm{C}-3$ and $\mathrm{C}-5$ were cladinose and desosamine, respectively.

The elemental analysis $(\mathrm{C}, \mathrm{H}, \mathrm{F}$ and $\mathrm{N})$ of VII was consistent with the formula $\mathrm{C}_{36} \mathrm{H}_{64} \mathrm{FNO}_{12}$.

Its FAB-MS showed the protonated molecular ion at $m / z 722$ and the ion $\mathrm{MH}^{+}-\mathrm{H}_{2} \mathrm{O}$ at $m / z 704$. The mass fragmentation pattern was similar to that showed by $(8 S)$-8-fluoroerythromycin $\mathrm{B}$. Peaks at $m / z 145,127$ and 109 showed that the sugar at C-3 was mycarose.

Treatment of $\mathbf{V}$ and VII in dilute hydrochloric acid (Scheme 2) yielded the same monoglycoside, whose structure was inferred to be 5-O-desosaminyl-(8S)-8-fluoroerythronolide B (IX) on the basis of elemental analysis, FAB-mass and ${ }^{1} \mathrm{H}$ NMR spectral data. Complementarily, the same mixture of $\alpha$ and $\beta$-anomers ( $\mathbf{X}$ and $\mathbf{X I}$ ) of methyl cladinoside was obtained by acid-catalyzed methanolysis of $\mathbf{V}$ and erythromycin A, whereas the $\alpha$ - and $\beta$-anomers (XII and XIII) of methyl mycaroside were derived from both VII and 3-O-mycarosylerythronolide B. In contrast to (8S)-8-fluoroerythromycins $\mathrm{A}(\mathrm{IV})$ and $\mathrm{C}(\mathrm{VI})$, which exist as an interconvertible mixture of tautomers, (8S)-8-fluoroerythromycins $\mathrm{B}(\mathrm{V})$ and D (VII) exist exclusively as the ketonic forms.

In agreement with the results of the biotransformation of (8S)-8-fluoroerythronolide A (I), we demonstrate that the glycosidases accept both (8S)-8-fluoroerythronolide B (II) and 3-O-mycarosyl-( $8 S$ )8 -fluoroerythronolide B (III) as possible substrates. It is worth noting that, also in this case, the $O$ methylation step is rate-limiting, leading to accumulation of (8S)-8-fluoroerythromycin D (VII) which is not completely converted to $(8 S)$-8-fluoroerythromycin B (V). Moreover, another enzyme, the C-12 hydroxylase ${ }^{15)}$, is clearly shown to possess a very strict substrate specificity, since ( $8 S$ )-8-fluoroerythromycin C (VI) and (8S)-8-fluoroerythromycin A (IV) are not produced. It is obvious from the results that this enzyme either does not recognize (8S)-8-fluoroerythromycin D (VII) or is not induced by it. This specificity, which seems to be the strictest among those of the enzymes of the last steps in the biosynthesis of erythromycins, also came out from the before mentioned conversion of 11- $O$-methyl ether of erythronolide B yielding only the 11-O-methylerythromycin B, and not the A-form.

\section{Acid Stability}

The importance of the fluorine atom at C-8 is clearly illustrated by the data of Table 1 where the acid stability at $\mathrm{pH} \mathrm{2,3}$ and 4 of the new (8S)-8-fluoroerythromycins is compared with that of erythromycin 
Table 1. Acid stability at $25^{\circ} \mathrm{C}$.

\begin{tabular}{cllr}
\hline \multirow{2}{*}{ Compounds } & \multicolumn{3}{c}{$\mathrm{t}_{\frac{1}{2}}{ }^{*}$} \\
\cline { 2 - 4 } & $\mathrm{pH} \mathrm{2}$ & $\mathrm{pH} \mathrm{3}$ & $\mathrm{pH} \mathrm{4}$ \\
\hline IV** $^{* *}$ & 9 & 82.5 & $>100$ \\
V & 3 & 45 & $>100$ \\
VI** & 1.65 & 41.5 & $>100$ \\
VII & 0.4 & 10 & $>100$ \\
Erythromycin A & 0.05 & 0.1 & 2
\end{tabular}

* The half-life in hours.

** Quantitative data were calculated by summing the areas of the two peaks corresponding to the ketonic and hemiketalic forms (HPLC analysis).

$\mathrm{A}^{18)}$. As reported before, (8S)-8-fluoroerythromycins A (IV) and C (VI) display a fluoroketonehemiketal tautomerism in these environments (Scheme 3).
Fig. 1. Average values of serum levels of erythromycin A and IV in rats after a single oral dose of $100 \mathrm{mg} / \mathrm{kg}$.

The standard error of the mean is represented by the vertical bars.

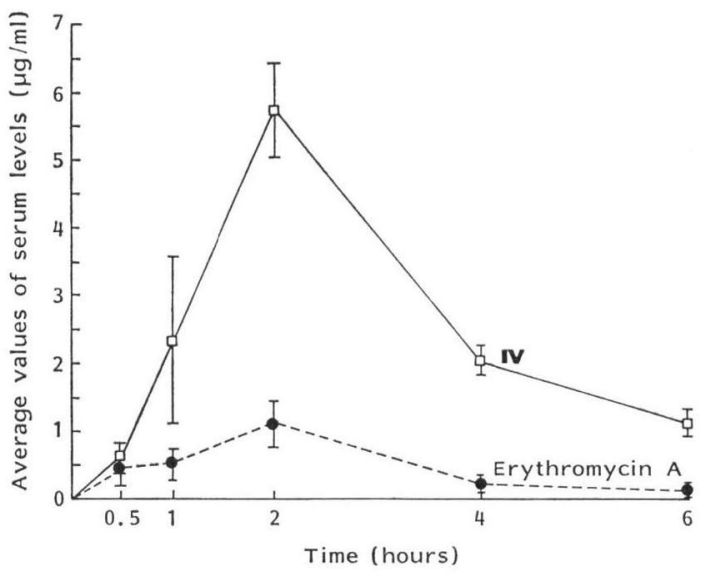

Biological Activity of the Conversion Products

Tables $2 \sim 4$ summarize the antimicrobial activity in vitro of the new fluoroerythromycins in com-

Table 2. Antibacterial activity of compounds IV, V, VI, VII compared to that of erythromycin A and erythromycin B (agar dilution method).

\begin{tabular}{|c|c|c|c|c|c|c|}
\hline \multirow[b]{2}{*}{ Organism } & \multicolumn{6}{|c|}{$\operatorname{MIC}(\mu \mathrm{g} / \mathrm{ml})$} \\
\hline & IV & $\mathbf{V}$ & VI & VII & $\begin{array}{c}\text { Erythro- } \\
\text { mycin } \\
\text { A }\end{array}$ & $\begin{array}{c}\text { Erythro- } \\
\text { mycin } \\
\text { B }\end{array}$ \\
\hline Staphylococcus aureus ATCC 6538P & 0.097 & 0.097 & 0.097 & 0.097 & 0.049 & 0.097 \\
\hline Staphylococcus aureus ATCC 14154* & $>25$ & $>25$ & $>25$ & $>25$ & $>25$ & $>25$ \\
\hline Staphylococcus aureus PRL 14** & 0.097 & 0.097 & 0.097 & 0.097 & 0.049 & 0.195 \\
\hline Streptococcus pyogenes ATCC 8668 & 0.012 & 0.024 & 0.024 & 0.024 & 0.012 & 0.024 \\
\hline Streptococcus pneumoniae ATCC 6303 & 0.024 & 0.049 & 0.024 & 0.024 & 0.012 & 0.024 \\
\hline $\begin{array}{l}\text { Streptococcus faecalis subsp. zymogenes } \\
\text { ATCC } 12958\end{array}$ & 0.195 & 0.195 & 0.097 & 0.097 & 0.097 & 0.195 \\
\hline Corynebacterium diphteriae PRL 24 & 0.012 & 0.006 & 0.012 & 0.006 & 0.006 & 0.012 \\
\hline Micrococcus luteus ATCC 9341 & 0.006 & 0.012 & 0.012 & 0.006 & 0.006 & 0.006 \\
\hline Micrococcus luteus ATCC 15957* & $>25$ & $>25$ & $>25$ & $>25$ & $>25$ & $>25$ \\
\hline Bacillus subtilis ATCC 6633 & 0.049 & 0.049 & 0.097 & 0.049 & 0.049 & 0.049 \\
\hline Haemophilus influenzae ATCC 19418 & 3.12 & 6.25 & 12.5 & 6.25 & 3.12 & 6.25 \\
\hline Neisseria gonorrhoeae ATCC 19424 & 0.049 & 0.097 & 0.195 & 0.097 & 0.049 & 0.097 \\
\hline Escherichia coli PRL 50 & 12.5 & 25 & 12.5 & 25 & 6.25 & 25 \\
\hline Klebsiella pneumoniae PRL 54 & 12.5 & $>25$ & 25 & $>25$ & 12.5 & 25 \\
\hline Proteus vulgaris ATCC 6380 & $>25$ & $>25$ & 25 & $>25$ & $>25$ & $>25$ \\
\hline Salmonella typhi PRL 8 & 12.5 & 25 & 12.5 & 12.5 & 12.5 & 25 \\
\hline Shigella sonnei PRL 5 & 25 & 25 & 25 & $>25$ & 12.5 & $>25$ \\
\hline Pseudomonas aeruginosa PRL 9 & $>25$ & $>25$ & 25 & 25 & $>25$ & $>25$ \\
\hline Clostridium perfringens ATCC 3624 & 0.78 & 0.39 & 6.25 & 3.12 & 1.56 & 1.56 \\
\hline Bacteroides fragilis ATCC 23745 & 0.195 & 0.195 & 0.78 & 0.39 & 0.195 & 0.195 \\
\hline Fusobacterium necrophorum ATCC 27852 & 1.56 & 3.12 & 12.5 & 6.25 & 3.12 & 6.25 \\
\hline
\end{tabular}

* Erythromycin-resistant

** Penicillin-resistant 
Table 3. Antibacterial activity of compounds IV, V, VI, VII compared to that of erythromycin A and erythromycin B (broth dilution method).

\begin{tabular}{|c|c|c|c|c|c|c|}
\hline \multirow[b]{2}{*}{ Organism } & \multicolumn{6}{|c|}{$\mathrm{MIC}(\mu \mathrm{g} / \mathrm{ml})$} \\
\hline & IV & $\mathbf{V}$ & VI & VII & $\begin{array}{l}\text { Erythro- } \\
\text { mycin } \\
\text { A }\end{array}$ & $\begin{array}{l}\text { Erythro- } \\
\text { mycin } \\
\text { B }\end{array}$ \\
\hline Staphylococcus aureus ATCC 6538P & 0.195 & 0.097 & 0.195 & 0.195 & 0.097 & 0.195 \\
\hline Streptococcus pyogenes ATCC 8668 & 0.097 & 0.024 & 0.049 & 0.049 & 0.024 & 0.024 \\
\hline Streptococcus pneumoniae ATCC 6303 & 0.049 & 0.049 & 0.097 & 0.049 & 0.024 & 0.049 \\
\hline $\begin{array}{l}\text { Streptococcus faecalis subsp. zymogenes } \\
\text { ATCC } 12958 \text {. }\end{array}$ & 0.39 & 0.39 & 0.39 & 0.39 & 0.39 & 0.39 \\
\hline Corynebacterium diphteriae PRL24 & 0.012 & 0.012 & 0.049 & 0.012 & 0.012 & 0.012 \\
\hline
\end{tabular}

Table 4. Bactericidal activity of compounds IV, V, VI, VII compared to that of erythromycin A and erythromycin B.

\begin{tabular}{lllllcc}
\hline & \multicolumn{5}{c}{ MBC $(\mu \mathrm{g} / \mathrm{ml})$} \\
\cline { 2 - 7 } \multicolumn{1}{c}{ Organism } & IV & V & VI & VII & $\begin{array}{c}\text { Erythro- } \\
\text { mycin } \\
\text { A }\end{array}$ & $\begin{array}{c}\text { Erythro- } \\
\text { mycin } \\
\text { B }\end{array}$ \\
\hline Staphylococcus aureus ATCC 6538 P & 3.12 & 3.12 & 3.12 & 3.12 & 1.56 & 6.25 \\
Streptococcus pyogenes ATCC 8668 & 0.78 & 0.195 & 0.78 & 0.39 & 0.39 & 0.195 \\
$\begin{array}{l}\text { Streptococcus pneumoniae ATCC 6303 } \\
\text { Streptococcus faecalis subsp. zymogenes }\end{array}$ & 0.195 & 0.049 & 0.195 & 0.195 & 0.097 & 0.195 \\
$\begin{array}{c}\text { ATCC 12958 } \\
\text { Corynebacterium diphteriae PRL 24 }\end{array}$ & 0.25 & 3.12 & 3.12 & 3.12 & 6.25 & 6.25 \\
\hline
\end{tabular}

parison with erythromycins A and B. The convertants (8S)-8-fluoroerythromycins A (IV) and B (V) showed the same spectrum and were active to the same extent as compared with the natural occurring erythromycins. When their potency was estimated ${ }^{38)}$ against Micrococcus luteus ATCC 9341, (8S)-8fluoroerythromycin B (V) had about $110 \%$ of the activity of erythromycin B, whereas ( $8 S$ )-8-fluoroerythromycin A (IV) had about $70 \%$ of the activity of erythromycin A. The lower potency in this latter case may be attributable to the fluoroketone-hemiketal tautomerism, should a minor activity of IVa be hypothesized. Comparison between $\mathbf{V}$ and erythromycin B shows that replacement of hydrogen by fluorine at C-8 does not affect the antibacterial activity, contrary to what happens with a corresponding hydroxyl substituent ${ }^{28,39)}$. To our knowledge, this is the first time that macrolide antibiotics derived by mutasynthesis are as active as the analogous natural antibiotics.

The high acid stability of $(8 S)$-8-fluoroerythromycins prompted us to further biological investigations. In Fig. 1 some preliminary data of the serum levels of ( $8 S$ )-8-fluoroerythromycin A (IV) in rats are reported in comparison with those of erythromycin A. In view of these results, (8S)-8-fluoroerythromycin A (IV) could be an attractive alternative to erythromycin A 2'-esters which, despite their good oral absorption, possess undesirable side effects ${ }^{40)}$ and must be hydrolyzed in vivo to be therapeutically effective ${ }^{41}$. More complete studies in vivo will be presented in a forthcoming paper.

\section{Experimental}

Materials

Erythromycin A was purified from a commercial product by crystallization from chloroform. Erythromycin B was prepared as reported previously ${ }^{39}$ from a mother liquor concentrate. The latter was 
obtained from an industrial strain of $S$. erythraeus after crystallization and removal of the majority of the erythromycin A. 3-O-Mycarosylerythronolide $\mathrm{B}^{37)}$ was isolated from the fermentation beers of LMC 1198, a blocked mutant of $S$. erythraeus.

\section{Analysis}

Elemental analyses were performed by Alfred Bernhardt Microanalytical Laboratories, Elbach über Engelskirchen, West Germany. All melting points were taken in open capillary tubes using a Tottoli apparatus (N. Büchi, Flawil, Switzerland) and are uncorrected. Optical rotations were determined at $20^{\circ} \mathrm{C}$ in $1 \%$ methanol solutions with a Schmidt-Haentsch polarimeter.

UV spectra were measured in methanol using a Varian Cary 210 spectrophotometer. IR spectra were obtained on a Perkin-Elmer 577 spectrophotometer for KBr disks $(0.001 \mathrm{~g}$ of substance in $0.2 \mathrm{~g}$ of $\mathrm{KBr})$. ${ }^{1} \mathrm{H}$ NMR spectra were obtained on a Varian $\mathrm{T}-60 \mathrm{~A}$ spectrometer at room temperature in pyridine- $d_{5}(c 0.05 \mathrm{~g} / \mathrm{ml})$. Chemical shifts are reported in ppm from tetramethylsilane (TMS) as internal reference. ${ }^{13} \mathrm{C}$ NMR spectra were recorded with a Varian XL-200-FT spectrometer at $50.3 \mathrm{MHz}$ in proton decoupled conditions at room temperature. Samples were dissolved in deuteriochloroform $(c$ $0.2 \mathrm{~g} / \mathrm{ml}$ ) containing TMS as internal reference. FAB-MS were carried out on VG Analytical 7070E mass spectrometer equipped with a FAB source and operating with a $6 \mathrm{kV}$ accelerating potential. Approximatively $0.5 \sim 1 \mu \mathrm{g}$ of sample dissolved in glycerol was used.

Thin-layer chromatography (TLC) was carried out on precoated silica gel $60 \mathrm{~F}_{254}$ plates (Merck) using acetone - chloroform - methanol - 10\% ammonium hydroxide (50: 50:1.4:2) as developing solvent system (three runs). Compounds were visualized by spraying the plates with anisaldehyde - acetic acid methanol - sulfuric acid $(1: 5: 90: 2)$. Colors developed after a few minutes at $80^{\circ} \mathrm{C}$. Antibiotics were also detected by bioautography on Micrococcus luteus ATCC 9341 seeded agar. This same strain was used as test organism to determine the antibiotic levels in the cultured broths and the biological potency of the isolated compounds by a standard agar diffusion method.

High performance liquid chromatography (HPLC) analyses were carried out according to a modification of a described procedure ${ }^{42}$. A Hewlett-Packard 1084 B liquid chromatograph equipped with a variable-wavelength detector at $210 \mathrm{~nm}$ and a Lichrosorb RP8 $10 \mu \mathrm{m}$ stainless steel column, $250 \times 4.6 \mathrm{~mm}$ i.d., was used. Flow rate of the mobile phase was $2.0 \mathrm{ml} /$ minute and the column was operated at $40^{\circ} \mathrm{C}$. Two mobile phases were employed: mobile phase 1 consisted of acetonitrile $-0.01 \mathrm{M}$ phosphate buffer pH 7.0 (40:60); mobile phase 2 consisted of acetonitrile - $0.01 \mathrm{M}$ phosphate buffer pH 7.0 (64:36). Acid stability trials of new antibiotics were carried out according to the method described in a previous paper $^{43)}$. Gas liquid chromatographies (GLC) were carried out on a Perkin-Elmer Model 900 B equipped with a glass column, $2,000 \times 2 \mathrm{~mm}$ i.d., packed with $4.3 \%$ Silicone OV 25 on $80 \sim 100$ mesh HP Chromosorb $\mathrm{W}$ and heated from $110^{\circ} \mathrm{C}$ to $160^{\circ} \mathrm{C}\left(6^{\circ} \mathrm{C} /\right.$ minute $)$. Nitrogen gas was used as a carrier at $30 \mathrm{ml} /$ minute and $2.8 \mathrm{~kg} / \mathrm{cm}^{2}$ inlet pressure.

Column Chromatography

Partition column chromatography was carried out in conformity with a reported method $^{44}$ ) using a column $(740 \times 24 \mathrm{~mm}$ i.d.) packed with silica gel 60, 70 230 mesh (Merck). Fifteen-milliliter fractions were collected at a flow rate of $1.0 \mathrm{ml}$ per minute and were tested by TLC and HPLC (mobile phase 2). Fractions containing one product only were combined and concentrated to dryness under reduced pressure. Residual buffer salts were removed from products by washing their chloroform solutions with water. Sephadex LH-20 (Pharmacia Fine Chemicals), particle size $25 \sim 100 \mu \mathrm{m}$, was refluxed three times for 30 minutes in a mixture of chloroform and methanol $(1: 1)$, filtered and dried at $40^{\circ} \mathrm{C}$ before beeing used for column chromatography ${ }^{45}$. Preparation and elution of the column was performed with a mixture of chloroform - hexane $(1: 1)$. Homogeneous fractions were combined and evaporated under reduced pressure.

Microorganism and Fermentation

The strain employed in the present investigation was Streptomyces erythraeus ATCC 31772 which was cultured as described in a previous paper ${ }^{15)}$. After 24 hours of cultivation, $500 \mu \mathrm{g} / \mathrm{ml}$ of either substrate, $(8 S)$-8-fluoroerythronolide A $(\mathbf{I})^{3)}$ or $\mathrm{B}(\text { III })^{3)}$ or 3-O-mycarosyl-(8S)-8-fluoroerythronolide $\mathrm{B}$ $(\text { III })^{4}$, was added into the culture and the cultivation was continued for a further 96 hours. Antibiotic 
production generally reached a maximum after 120 hours (HPLC, mobile phase 2 ), corresponding to the total conversion of the added substrate (HPLC, mobile phase 1). TLC and bioassay were also used to monitor the process.

\section{Isolation of (8S)-8-Fluoroerythromycins A (IV) and C (VI)}

The broth (2.1 liters) to which $1.0 \mathrm{~g}$ of $(8 S)$-8-fluoroerythronolide A (I) had been added, was filtered over Celite to remove mycelia and the filtrate was clarified by the addition of equal volumes of a $10 \%$ aqueous solution of zinc sulfate and a $4 \%$ solution of sodium hydroxide. After centrifugation, the clear supernatant was extracted with ethyl acetate at $\mathrm{pH} 9.8$. The organic extract was washed with water and dried on anhydrous sodium sulfate. Evaporation of the ethyl acetate under reduced pressure left $1.36 \mathrm{~g}$ of yellow foam. Partition column chromatography of this material gave $0.35 \mathrm{~g}$ of $(8 S)$-8-fluoroerythromycin A (IV, fractions $90 \sim 174)$ and $0.345 \mathrm{~g}$ of $(8 S)$-8-fluoroerythromycin C (VI, fractions $280 \sim$ 400). Crystallization from ethanol yielded $0.230 \mathrm{~g}$ of pure $\mathrm{IV}$, as prisms: $\mathrm{mp} 183 \sim 184^{\circ} \mathrm{C} ;[\alpha]_{\mathrm{D}}-54.9^{\circ}$; UV $283 \mathrm{~nm}(\varepsilon 17.9) ;{ }^{1} \mathrm{H}$ NMR $\delta 2.15\left(\mathrm{NMe}_{2}\right.$ of IV), $2.20\left(\mathrm{NMe}_{2}\right.$ of IVa), 3.36 (OMe of IVa), 3.45 (OMe of IV); IR 3520, 3480 (sh.), 3250 (broad), 1735, 1720, 1460, 1380, 1345, 1330, 1305, $1170 \mathrm{~cm}^{-1}$; FAB-MS $m / z 752\left(\mathrm{MH}^{+}\right)$.

Anal. Calcd. for $\mathrm{C}_{37} \mathrm{H}_{86} \mathrm{FNO}_{13}$ : C 59.10, H 8.85, F 2.52, N 1.86 .
Found:
C $59.09, \mathrm{H} 8.89, \mathrm{~F} 2.59, \mathrm{~N} 1.88$.

Pure VI $(0.145 \mathrm{~g})$ was obtained as prisms by crystallization from ethanol: $\mathrm{mp} 217 \sim 218^{\circ} \mathrm{C}$; $[\alpha]_{\mathrm{D}}$ $-42.4^{\circ}$; UV $284 \mathrm{~nm}(\varepsilon 23.2) ;{ }^{1} \mathrm{H}$ NMR $\delta 2.10\left(\mathrm{NMe}_{2}\right.$ of VI), $2.18\left(\mathrm{NMe}_{2}\right.$ of VIa); IR 3550, 3500, 3440 (sh), 3300 (broad), 1730, 1455, 1410, 1380, 1360, 1340, 1330, 1305, 1170 (broad) $\mathrm{cm}^{-1}$; FAB-MS $m / z$ $738\left(\mathrm{MH}^{+}\right)$.

Anal. Calcd. for $\mathrm{C}_{36} \mathrm{H}_{64} \mathrm{FNO}_{13}$ : C 58.60, $\mathrm{H}$ 8.74, F 2.57, N 1.90 .
Found:
C $58.47, \mathrm{H} 8.87, \mathrm{~F} 2.60, \mathrm{~N} 1.82$.

Isolation of (8S)-8-Fluoroerythromycins $\mathrm{B}(\mathrm{V})$ and $\mathrm{D}$ (VII)

The broth (2.1 liters) to which $1.0 \mathrm{~g}$ of $(8 S)$-8-fluoroerythronolide B (II) had been added, was clarified, extracted and purified by partition column chromatography as reported before. Fractions $18 \sim 32$ $(0.35 \mathrm{~g})$ were crystallized from ethanol to give $0.15 \mathrm{~g}$ of pure $(8 S)$-8-fluoroerythromycin $\mathrm{B}(\mathrm{V})$ as prisms: $m p 164 \sim 166^{\circ} \mathrm{C} ;[\alpha]_{\mathrm{D}}-63.1^{\circ}$; UV $285 \mathrm{~nm}(\varepsilon 29.5) ;{ }^{1} \mathrm{H}$ NMR $\delta 2.15\left(\mathrm{NMe}_{2}\right) 3.45(\mathrm{OMe})$; IR 3480 (broad), 1735, 1465, 1385, 1330, 1305, $1170 \mathrm{~cm}^{-1}$; FAB-MS $m / z 736\left(\mathrm{MH}^{+}\right)$.

Anal. Calcd. for $\mathrm{C}_{37} \mathrm{H}_{68} \mathrm{FNO}_{12}$ : C 60.39, H 9.04, F 2.58, N 1.90. Found:

C $60.31, \mathrm{H} 9.09, \mathrm{~F} 2.60, \mathrm{~N} 1.88$.

(8S)-8-Fluoroerythromycin D (VII) was eluted in subsequent fractions $(55 \sim 105)$ and isolated as a glass $(0.32 \mathrm{~g})$. Crystallization from ethanol afforded $0.15 \mathrm{~g}$ of an analytical sample: $\mathrm{mp} 213 \sim 215^{\circ} \mathrm{C}$; $[\alpha]_{\mathrm{D}}-59.9^{\circ}$; UV $285 \mathrm{~nm}(\varepsilon 30.8) ;{ }^{1} \mathrm{H}$ NMR $\delta 2.13\left(\mathrm{NMe}_{2}\right)$; IR 3600, 3520, 3300 (broad), 1730, 1460, $1420,1385,1370,1310,1160 \mathrm{~cm}^{-1}$ : FAB-MS $m / z 722\left(\mathrm{MH}^{+}\right)$.

Anal. Calcd. for $\mathrm{C}_{37} \mathrm{H}_{68} \mathrm{FNO}_{12}$ : C 59.89, $\mathrm{H}$ 8.94, F 2.63, N 1.94 . Found:

C $59.87, \mathrm{H} 8.85, \mathrm{~F} 2.63, \mathrm{~N} 1.88$.

The culture (1.0 liter) fed $0.50 \mathrm{~g}$ of 3-O-mycarosyl-( $8 S$ )-8-fluoroerythronolide $\mathrm{B}$ (III), was processed in the same way as reported above. Partition column chromatography of the residue from the solvent extraction, gave $0.115 \mathrm{~g}$ of $(8 S)$-8-fluoroerythromycin $\mathbf{B}(\mathrm{V})$ and $0.095 \mathrm{~g}$ of $(8 S)$-8-fluoroerythromycin D (VII), identical with those prepared as described before.

Acid Cleavage

1) Isolation of 5-O-Desosaminyl-(8S)-8-fluoroerythronolide A (VIII): A solution of $0.752 \mathrm{~g}(0.001$ mol) of (8S)-8-fluoroerythromycin A (IV) or $0.738 \mathrm{~g}(0.001 \mathrm{~mol})$ of $(8 S)$-8-fluoroerythromycin C (VI) in $75 \mathrm{ml}$ of a pH 2 hydrochloric acid buffer, was allowed to stand at room temperature for 24 hours. The complete disappearance of IV and VI was monitored by TLC and HPLC (mobile phase 2). The reaction mixture was poured into a saturated sodium hydrogen carbonate solution, and the product was extracted with ethyl acetate. The combined organic phase was dried over anhydrous sodium sulfate and concentrated under reduced pressure. The resulting solid residue was purified on Sephadex LH-20 to yield, after crystallization from ethyl ether - hexane, $0.145 \mathrm{~g}$ of 5-O-desosaminyl-(8S)-8-fluoroerythronolide A(VIII): $\mathrm{mp} 120 \sim 124^{\circ} \mathrm{C}$; $[\alpha]_{\mathrm{D}}-18.5^{\circ}$; UV $287 \mathrm{~nm}(\varepsilon 22.5) ;{ }^{1} \mathrm{H}$ NMR $\delta 2.12\left(\mathrm{NMe}_{2}\right) ;$ IR 3460, 1725, $1460,1380,1350,1325,1170 \mathrm{~cm}^{-1}$; FAB-MS $\mathrm{m} / \mathrm{z} 594\left(\mathrm{MH}^{+}\right)$. 
Anal. Calcd. for $\mathrm{C}_{29} \mathrm{H}_{52} \mathrm{FNO}_{10}$ : C 58.67, H 8.83, F 3.20, N 2.36.

Found:

C 58.65, H 8.91, F 3.03, N 2.28.

2) Isolation of 5-O-Desosaminyl-(8S)-8-fluoroerythronolide B (IX): A solution prepared from $0.736 \mathrm{~g}(0.001 \mathrm{~mol})$ of $(8 S)$-8-fluoroerythromycin B (V) or $0.722 \mathrm{~g}(0.001 \mathrm{~mol})$ of $(8 S)$-8-fluoroerythromycin $\mathrm{D}$ (VII) and $75 \mathrm{ml}$ of a $\mathrm{pH} 2$ hydrochloric acid buffer, was kept at room temperature 19 hours, until the complete disappearance of the starting product was checked by TLC and HPLC (mobile phase 2). The reaction solution was adjusted to $\mathrm{pH} 9.0$ with $5 \%$ sodium hydroxide and immediately extracted with ethyl acetate. The organic layers were combined, washed with water, dried over anhydrous sodium sulfate and evaporated under reduced pressure. The resulting colorless foam was purified on Sephadex LH-20 to yield $0.215 \mathrm{~g}$ of pure 5 - $O$-desosaminyl- $(8 S)$-8-fluoroerythronolide $\mathbf{B}$ (IX): $\mathrm{mp} 116 \sim 120^{\circ} \mathrm{C}$; $[\alpha]_{\mathrm{D}}-43.1^{\circ}$; UV $284 \mathrm{~nm}(\varepsilon 35.6) ;{ }^{1} \mathrm{H}$ NMR $\delta 2.10\left(\mathrm{NMe}_{2}\right)$; IR 3450 (broad), 1725, 1460, 1380, 1330, $1170 \mathrm{~cm}^{-1}$; FAB-MS $\mathrm{m} / z 578\left(\mathrm{MH}^{+}\right)$.

Anal. Calcd. for $\mathrm{C}_{29} \mathrm{H}_{52} \mathrm{FNO}_{9}$ : C 60.29, H 9.07, F 3.29, N 2.42.

Found:

C $60.23, \mathrm{H} 9.09, \mathrm{~F} 3.26, \mathrm{~N} 2.31$.

3) Methanolysis of (8S)-8-Fluoroerythromycins A (IV) and B (V): A solution of $0.037 \mathrm{~g}(0.05$ mmol) of ( $8 S$ )-8-fluoroerythromycin A (IV) or B (V) in $2 \mathrm{ml}$ of methanol containing $1 \%$ hydrogen chloride, was allowed to stand at room temperature for 22 hours. The reaction solution was poured into a saturated sodium hydrogen carbonate solution, concentrated under reduced pressure to remove methanol and then extracted with ethyl acetate. After drying on anhydrous sodium sulfate, the extract was concentrated under reduced pressure. GLC analysis of the residue showed two components with retention times of $3.8(18 \%)$ and $4.5(82 \%)$ minutes, identical to those obtained from the corresponding cleavage of erythromycin A.

4) Methanolysis of (8S)-8-Fluoroerythromycins C (VI) and D (VII): GLC analysis of the mixture obtained by methanolysis of ( $8 S$ )-8-fluoroerythromycins C (VI) and D (VII) showed two components with retention times of $3.2(35 \%)$ and $6.7(65 \%)$ minutes, identical to those obtained from the corresponding cleavage of 3-O-mycarosylerythronolide $\mathrm{B}$.

\section{Antibacterial Activity In Vitro}

Minimal inhibitory concentrations (MIC) were determined by the standard two-fold dilution method using Müller Hinton (MH) medium (Difco). For the genera Streptococcus and Corynebacterium the MH medium was added with $5 \%$ horse serum. The genera Haemophilus, Neisseria and the anaerobes were tested on GC Completed Medium (Difco). Incubation was performed in gas pack anaerobic jar (BBL) for anaerobes, in candle jar for the others. Bacterial strains used for susceptibility determinations were cultures regularly employed in our screening tests. The strains coded PRL (Pierrel Research Laboratories) have been collected and identified by standard criteria in these laboratories. Bacterial cultures containing approximatively $10^{6} \sim 10^{7}$ viable cells $/ \mathrm{ml}$ were prepared from overnight cultures. One loopful of the cultures was inoculated on the agar plates containing antibiotics. The agar plates were incubated at $37^{\circ} \mathrm{C}$ for 24 hours, and MIC was defined as the lowest concentration that prevented visible growth. The usual diffusion cylinder method ${ }^{38)}$ was used to estimate the potency of the new antibiotics against Micrococcus luteus ATCC 9341. For a selected number of bacterial strains the MIC were determined in MH broth. For these strains the minimal bactericidal concentrations (MBC) were also determined by further subculturing in the medium without antibiotic the cultures that after 24 hours did not show visible growth.

Absorption Studies in Rats

Female Sprague-Dawley rats weighing $160 \sim 180 \mathrm{~g}$ were given $100 \mathrm{mg} / \mathrm{kg}$ of antibiotic orally. Six rats were sacrificed at each interval, blood samples were withdrawn and sera separated by centrifugation. The sera were stored at $-20^{\circ} \mathrm{C}$ until assay. Serum levels were determined by the usual diffusion cylinder plate method ${ }^{38)}$ using Micrococcus luteus ATCC 9341.

\section{Acknowledgments}

We wish to thank Mr. S. Silingardi and Mr. M. Di Bitetro for HPLC and GLC determinations, Mr. R. Pezzali for his support in biological activity studies. Our gratitude is also due to Dr. S. Bradamante (Institute 
of Industrial Chemistry, Milan University, Italy) and Dr. P. BRooks (VG Analytical) for their kind permission to use Varian XL-200-FT and VG 7070E instruments, respectively.

\section{References}

1) Goldman, P.: The carbon-fluorine bond in compounds of biological interest. Science 164: 1123 1130, 1969

2) Stern, A. M.; B. M. Foxman, A. H. Tashian, Jr. \& R. H. Abeles: Dl-threo- $\beta$-Fluoroaspartate and Dlthreo- $\beta$-fluoroasparagine: Selective cytotoxic agents for mammalian cells in culture. J. Med. Chem. 25: $544 \sim 550,1982$, and references cited therein

3) Toscano, L.; G. Fioriello, S. Silingardi \& M. Inglesi: Preparation of (8S)-8-fluoroerythronolide A and $(8 S)$-8-fluoroerythronolide $\mathrm{B}$, potential substrates for the biological synthesis of new macrolide antibiotics. Tetrahedron, in press

4) Toscano, L. \& E. Seghetri: Transformation of 3-O-mycarosylerythronolide B, an intermediate of erythromycin biogenesis, into 3-O-mycarosyl-(8S)-8-fluoroerythronolide B using trifluoromethyl hypofluorite $\left(\mathrm{CF}_{3} \mathrm{OF}\right)$. Tetrahedron Lett., in press.

5) Gerstenberger, M. R. C. \& A. HaAs: Methods of fluorination in organic chemistry. Angew. Chem. Int. Ed. Engl. 20: 647 667, 1981

6) Penglis, A. A. E.: Fluorinated carbohydrates. In Advances in Carbohydrate Chemistry and Biochemistry. Ed. by R. S. Tipson \& D. Horton, pp. 195 285, Academic Press, New York, 1981

7) Barton, D. H. R.: New methods of specific fluorination. Pure Appl. Chem. 21:285 293, 1970

8) Foster, A. B. \& J. H. Westwood: The synthesis of fluorinated carbohydrates. Pure Appl. Chem. 35: $147 \sim 168,1973$

9) Barton, D. H.R.: The invention of reactions useful for the synthesis of specifically fluorinated natural products. Pure Appl. Chem. 49: 1241 1249, 1977

10) Barton, D. H. R.; R. H. Hesse, L. Ogunkoya, N. D. Westcott \& M. M. Pechet: Organic reactions of fluoro-oxy-compounds. Fluorination of griseofulvin. J. Chem. Soc. Perkin I 1972: 2889 2891, 1972

11) Kurath, P.; P. H. Jones, R. S. Egan \& T. J. Perun: Acid degradation of erythromycin A and erythromycin B. Experientia 27: 362, 1971

12) Toscano, L.; E. Seghetti, M. Inglesi \& G. Fioriello: Acid-catalized modifications of erythronolide A and erythronolide B. Preparation of 9,10-anhydroerythronolide A and B 6,9-hemiketals. Gazz. Chim. Ital., in press

13) Kavanagh, F. \& L. J. Dennin: Erythromycin. In Analytical Microbiology. Ed. by F. Kavanagh, pp. 289 294, Academic Press, New York, 1963

14) Daum, S. J. \& J. R. Lemke: Mutational biosynthesis of new antibiotics. Ann. Rev. Microbiol. 33: 241 265,1979

15) Spagnoli, R. \& L. Toscano: Erythronolide A glycosidation to erythromycin A by a blocked mutant of Streptomyces erythraeus. J. Antibiotics 36: 435 437, 1983

16) BARber, M.; R. S. Bordoli, R. D. Sedgwick \& A. T. Tyler: Fast atom bombardment of solids (F.A.B.): a new ion source for mass spectrometry. J. Chem. Soc., Chem. Comm. 1981: 325 327, 1981

17) Parr, V. C.; B. N. Green, R. H. Bateman \& J. C. Bill: Structural studies of cephalosporins using a fast atom bombardment source. Presented at the 29th Ann. Conf. of Mass Spectrom. \& Allied Topics, Minneapolis, 1981

18) Barber, M.; R. S. Bordoli, R. D. Sedgwick, A. N. Tyler \& B. W. Bycroft: Fast atom bombardment mass spectrometry of bleomycin $\mathrm{A}_{2}$ and $\mathrm{B}_{2}$ and their metal complexes. Biochem. Biophys. Res. Comm. 101: $632 \sim 638,1981$

19) Mitscher, L. A. \& H. D. H. Showalter: Chemical ionization mass spectra of macrolide antibiotics. J. Chem. Soc., Chem. Comm. 1972: 796 797, 1972

20) Rinehart, K. L. \& J. C. Cook, Jr.: Field desorption mass spectra of antibiotics. J. Antibiotics 27: 1 13, 1974

21) Majer, J.; J. R. Martin, R. S. Egan \& J. W. Corcoran: Antibiotic glycosides. 8. Erythromycin D, a new macrolide antibiotic. J. Am. Chem. Soc. 99: 1620 1622, 1977

22) Wiley, P. F.; M. V. Sigal, Jr., O. Weaver, R. Monahan \& K. Gerzon: Erythromycin. XI. Structure of erythromycin B. J. Am. Chem. Soc. 79: 6070 6074, 1957

23) LeMahieu, R. A.; M. Carson \& R. W. Kierstead: Glycoside cleavage reactions on erythromycin A. Preparation of erythronolide A. J. Med. Chem. 17: 953 956, 1974

24) Jones, P. H. \& E. K. Rowley: Chemical modifications of erythromycin antibiotics. I. 3'-De(dimethyl- 
amino)erythromycin A and B. J. Org. Chem. 33: 665 670, 1968

25) Wiley, P. F.; R. Gale, C. W. Pettinga \& K. Gerzon: Erythromycin. XII. The isolation, properties and partial structure of erythromycin C. J. Am. Chem. Soc. 79: 6074 6077, 1957

26) Tadanier, J.; J. R. Martin, R. S. Egan, A. W. Goldstein, R. S. Stanaszek, E. Hirner \& F. Fischer: Some chemical and stereochemical modifications of the erythromycin lactone rings. J. Org. Chem. 39: $2495 \sim 2501,1974$

27) Tadanier, J.; P. Kurath, J. R. Martin, J. B. McAlpine, R. S. Egan, A. W. Goldstein, S. L. Mueller \& D. A. Dunnigan: C (8) Epimeric 8-hydroxy-erythromycins-A. Helv. Chim. Acta 56: 2711 2719, 1973

28) Kurath, P.; J. R. Martin, J. Tadanier, A. W. Goldstein, R. S. Egan \& D. A. Dunnigan: C(8) Epimeric 8-hydroxy-erythromycins-B. Helv. Chim. Acta 56: 1557 1565, 1973

29) Jones, P. H.; T. J. Perun, E. K. Rowley \& E. J. Baker: Chemical modifications of erythromycin antibiotics. 3. Synthesis of $4^{\prime \prime}$ and 11 esters of erythromycin A and B. J. Med. Chem. 15: 631 634, 1972

30) Breitmaier, E. \& W. Voelter: ${ }^{13}$ C NMR Spectroscopy. Vol. 5 of Monographs in Modern Chemistry. Ed. by H. F. EbeL, pp. $141 \sim 144$, Verlag Chemie GmbH, Weinheim/Bergstr., 1974

31) Egan, R. S.; J. R. Martin, J. B. Mcalpine, P. Kurath, R. S. Stanaszek \& A. W. Goldstein: The structures of the $m$-chloroperbenzoic acid oxidation products of 8,9-anhydroerythromycin A- and B-6,9hemiacetal and of (8S)-8-hydroxyerythromycin B. J. Antibiotics 31:55 62, 1978

32) Nourse, J. G. \& J. D. Roberts: Nuclear magnetic resonance spectroscopy. Carbon-13 spectra of some macrolide antibiotics and derivatives. Substituent and conformational effects. J. Am. Chem. Soc. 97: 4584 4594, 1975

33) Perun, T. J.; J. R. Martin \& R. S. Egan: Cyclic phenylboronates as hydroxyl protecting groups in the synthesis of monoesters of macrolide aglycones. J. Org. Chem. 39: 1490 1493, 1974

34) Martin, J. R.; R. S. Egan, T. J. Perun \& A. W. Goldstein: 8-epi-Erythronolide B and its metabolic fate in fermentations of Streptomyces erythreus. Tetrahedron 29: 935 940, 1973

35) Kurath, P. \& R. S. Egan (Abbott Labs.): Erythronolide B derivatives. U. S. Patent: 3,697,547, Oct. 10, 1972. [Chem. Abstr. 77: 164536 v, 1972]

36) Corcoran, J. W.: Biochemical mechanisms in the biosynthesis of the erythromycins. In Antibiotics, Vol. IV. Biosynthesis. Ed. by J. W. Corcoran, pp. 132 174, Springer-Verlag, Berlin, 1981

37) Martin, J. R.; T. J. Perun \& R. L. Girolami: Studies on the biosynthesis of the erythromycins. I. Isolation and structure of an intermediate glycoside, 3- $\alpha$-L-mycarosylerythronolide B. Biochemistry 5: 2852 2856, 1966

38) Grove, D. C. \& W. A. Randall: Assay Methods of Antibiotics. A Laboratory Manual, pp. 96 98, Medical Encyclopedia Inc., New York, 1955

39) Krowicki, K. \& A. ZAmoJsKI: Chemical modification of erythromycins. IV. 8-Hydroxyerythromycin B. J. Antibiotics 26: 587 592, 1973

40) Wood Sell, S. H. \& J. T. Wilson: Erythromycin and troleandomycin. In Antimicrobial Therapy. Ed. by B. M. KAGAN, pp. $71 \sim 82$, W. B. Saunders Co., Philadelphia, 1974

41) Tardrew, P. L.; J. C. H. Mao \& D. Kenney: Antibacterial activity of 2 '-esters of erythromycin. Appl. Microbiol. 18: 159 165, 1969

42) Tsus, K. \& J. F. Goetz: High-performance liquid chromatographic determination of erythromycin. J. Chromatogr. 147: 359 367, 1978

43) Spagnoli, R.; L. Cappelletti \& L. Toscano: Biological conversion of erythronolide B, an intermediate of erythromycin biogenesis, into new "hybrid" macrolide antibiotics. J. Antibiotics 36: 365 375, 1983

44) Oleinick, N. L. \& J. W. Corcoran: Two types of binding of erythromycin to ribosomes from antibioticsensitive and -resistant Bacillus subtilis 168. J. Biol. Chem. 244: 727 735, 1969

45) ÄNGgÅRD, E. \& H. Bergkvist: Group separation of prostaglandins on Sephadex LH-20. J. Chromatogr. 48: $542 \sim 544,1970$ 